\title{
Las dos caras de Jano: la imagen del bárbaro en el Imperio romano
}

\author{
The two faces of Janus: the image of the Barbarian \\ in the Roman Empire
}

\author{
Miguel Ángel Ramírez Batalla*
}

\begin{abstract}
RESUMEN
Este artículo estudia las formas en que los romanos vieron a los bárbaros a través de sus textos para reforzar su propio sentido de identidad. Los romanos aprovecharon el legado griego para dibujar al bárbaro como el otro desde dos perspectivas: la

bestia amenazante que representa lo opuesto a los ideales clásicos y el buen salvaje que sirve como punto de reflexión y crítica de la propia cultura. Sin embargo, debido a las difíciles relaciones que Roma mantuvo con los grupos bárbaros a partir del siglo II d.C., la imagen negativa sobre los bárbaros se impuso en la mentalidad romana. Los bárbaros fueron vistos con varios vicios y defectos en una representación tradicional que dificultó las relaciones entre romanos y bárbaros. $\mathrm{Ya}$ sea cualquier retrato, éste obedecía más a estereotipos y lugares comunes que ignoraban las modificaciones históricas de los bárbaros y que remitían a patrones habituales de pensamiento. Esto alimentó un ambiente que sistemáticamente excluía a los bárbaros y los consideraba inferiores.
\end{abstract}

ABSTRACT

This article studies the ways that Romans saw Barbarians through their texts to reinforce their own sense of identity. Romans made use of the Greek legacy to design the Barbarian as the other from two perspectives: the menacing beast that represents the opposite to classical ideals, and the good savage who serves like a point of reflection and critics of their own culture. However, because of the difficult relations between Rome and Barbarian groups since the second century A.D., the negative image prevailed in the Roman mentality. Barbarians were seen with several vices and defects in a traditional representation which made difficult the relations between Romans and

Barbarians. Any description is based on stereotypes and common places that ignored the historical modifications of the Barbarians and resorted to habitual patrons of thought. It nourished an environment that systematically excluded the Barbarians and considered them inferior.

* Facultad de Filosofía y Letras, Universidad Nacional Autónoma de México (Circuito Interior s/n, Ciudad Universitaria, Coyoacán, México D.F.). E-mail: urbs753@gmail.com.

Artículo basado en la comunicación leída el 25 de Mayo de 2009, en la VIII edición del Encuentro de Jóvenes Investigadores de Historia Antigua de la Universidad Complutense de Madrid. 


\begin{abstract}
PALABRAS CLAVE: KEYWORDS:
Roma, bárbaros, identidad, imagen, tradición, exclusión, estereotipos.

Rome, Barbarians, identity, image, tradition, exclusion, stereotypes.
\end{abstract}

Los grupos humanos no sólo se mantienen unidos por razones económicas o políticas, sino también por cuestiones ideológicas. Para mantenerse unida una comunidad procura resaltar las similitudes que tienen sus miembros y minimizar sus diferencias, del mismo modo requiere distinguirse de los demás grupos humanos. Una colectividad necesita verse en el espejo de otra para resaltar los atributos que considera propios y los rasgos que imagina como ajenos. De tal manera, un grupo se define mediante una serie de cualidades positivas que provocan un sentido de pertenencia en sus integrantes y que son el parámetro para ver a quien no es como uno. La forma en que se concibe al otro suele darse en términos negativos para que quien realiza ese cotejo sienta orgullo por pertenecer a su grupo y vea diferente a quien no está dentro de él ${ }^{1}$. Como sucede en el interior de un grupo que define sus rasgos, la mayoría de las peculiaridades que definen al otro son creaciones que responden a prejuicios e imágenes ficticias, los cuales toman fuerza y presencia en la medida en que se repiten.

El mundo grecorromano no fue inmune a esta situación: griegos y romanos idearon al bárbaro como un ser distinto a ellos. La unidad de los griegos y, por ende, su identidad, se basaba en la lengua, las costumbres, la religión y un origen étnico común que oponían a los no griegos imaginarios y reales ${ }^{2}$. Aunque el significado primigenio del término bárbaro es el de extranjero, el que no habla griego, el término rápidamente adquirió matices negativos. Los griegos creían en la supremacía de su cultura y sus instituciones políticas, tenían la certeza de que pertenecían a una sociedad superior basada en la pólis, el mejor escenario de la convivencia humana, y en su capacidad para crear leyes y seguirlas en términos morales y cívicos. Esto se plasmaba en la habilidad individual de controlar las pasiones y subordinar sus deseos a la ley escrita, lo cual era la garantía de una sociedad organizada. En cambio, una particularidad esencial de los bárbaros era su incapacidad de desarrollar un sistema social de coexistencia basado en leyes, lo que los llevaba a un estado de servidumbre ${ }^{3}$. En esta perspectiva, los bárbaros eran incapaces de lograr una reforma interna del hombre en lo moral y una prolongación del dominio humano sobre la physis. Los griegos pensaban que la mayoría de los bárbaros eran seres nómadas que estaban en el estrato más bajo del avance humano: eran guerreros errantes, su principal ocupación era la caza y los frutos silvestres para obtener el sustento, no usaban el arado y no trabajaban los campos, por lo que no podían llevar una vida sedentaria. Sus formas políticas, entonces,

1 La bibliografía abunda para estos temas, algunos autores destacables: Anderson (1997: 7-23); Hernando (2002: 17-20); Gall (2004: 225-26).

2 Hdt. 8.144.

3 Mazzolani (1970:18). 
eran primitivas y simples, y la justicia no se basaba en leyes escritas que reglamentaran la convivencia en sociedad ${ }^{4}$. En caso de que tuvieran leyes, como los persas, éstas los sometían a la autoridad despótica del rey de reyes. Esto llevó a Aristóteles a señalar que los bárbaros estaban en una condición similar a la servil, lo cual los destinaba a someterse a los griegos ${ }^{5}$.

Roma asimiló gran parte del legado griego para fortalecer su imagen y justificar su dominio sobre otros pueblos. Cuando se consolidó política e ideológicamente, el Imperio romano se presentó como el oasis en que la civilización clásica era defendida de los demás pueblos que eran la antítesis de los valores que el Imperio protegía ${ }^{6}$. Por ello, en el pensamiento romano hay dos posiciones dominantes hacia los bárbaros: el rechazo hostil, que ve al bárbaro como un enemigo amenazante con los peores vicios; y la curiosidad etnológica que toma al bárbaro como motivo de reflexión y crítica de la cultura propia. Ambas posturas responderían a contextos particulares.

La primera postura considera al bárbaro como un ser incapaz de elevarse de su condición primitiva al carecer de la educación clásica. Las particularidades con las que se dibuja al bárbaro son ideadas como naturales, esto es, obedecen a una esencia inmutable y opuesta a las cualidades romanas. Un ejemplo es la manera en que Julio César describe a los bárbaros de las Galias y Britania: les atribuye propensión a los cambios y al disimulo, lo que explica sus constantes levantamientos, su perfidia los lleva a romper tratados que han celebrado con Roma, y su ingratitud no toma en cuenta los beneficios recibidos por los romanos. La resistencia gala es calificada de injuria y locura; su rechazo al dominio romano es rebelión. Son mentirosos y traicioneros al no respetar los acuerdos y al utilizar ardides para atacar a los romanos. Así, por ejemplo, en plena campaña gala, Julio César les señala estas actitudes a los embajadores helvecios y pregunta: « ¿podía entonces también deponer la memoria de las recientes injurias? ¿Que oponiéndose él, intentaran por la fuerza su camino a través de la provincia; que a los heduos, que a los ambarros, que a los alóbroges hubieran vejado? El que tan insolentemente se gloriaran de su victoria y que admiraran que él por tanto tiempo soportara impunemente sus injurias, atañía lo mismo ${ }^{7}$. Al describir las costumbres galas y germanas, recalca los hábitos extraños a los romanos para enfatizar el abismo que existía entre ambas sociedades. El cuadro de sus costumbres está orientado a fortalecer la fama bélica de los galos. En los comentarios sobre la estructura social y económica, Julio César resalta la inexistencia de la propiedad privada, el carácter comunal de la tierra, y la poligamia ${ }^{8}$. Sin duda, el general romano toma los hábitos romanos como parámetros al analizar los galos. Julio César era un escritor cuidadoso e inteligente. Al dejar claros los rasgos que distanciaban a los romanos de estos pueblos incultos, maneja conceptos que debieron ser los de sus

\footnotetext{
4 Amm Marc. 14.4.3-6.

5 Arist. Pol. 1252 b.

6 Algonza Roldán y Muñoz (1993: 48-53); Mazzolani (1970: 195).

7 Caes. BG 1.14. Traducción de Rubén Bonifaz Nuño. Vid Petrochilos (1994: 35-37).

8 Caes. BG 4.3; $5.14 ; 6.22$.
} 
lectores, habituados a ver a los bárbaros como seres opuestos a ellos; esos prejuicios le sirven para justificar su empresa.

La segunda postura, que utiliza a los otros para cuestionar la propia cultura, se da entre los romanos cuando no estaban conformes con su sistema político y las condiciones sociales; entonces se cuestionaban sobre los logros de su propia cultura y volteaban a ver a los bárbaros para reflexionar sobre su propia condición. Aun con sus beneficios, la civilización también tenía un lado negativo y llevaba el germen del declive. Julio César decía que los belgas eran los galos más fuertes «porque del modo de vida y la civilización de la provincia distan muchísimo y con mínima frecuencia acuden a ellos los mercaderes e importan lo que tiende a afeminar los ánimos, y están próximos a los germanos que habitan más allá del Reno, con quienes de continuo mueven guerra ${ }^{9}$. Por su parte, Tácito decía que una táctica de Julio Agrícola en Britania fue mostrar los placeres romanos a los nobles britanos. La lengua latina, la vestimenta romana, los baños y banquetes sedujeron a los britanos y fortalecieron el dominio romano en la provincia ${ }^{10}$. Así pues, este panorama abría algunas cuestiones: ¿la vida civilizada provocaba la relajación de las costumbres? ¿La civilización era sinónimo de decadencia? Los romanos pensaban que tal vez la paz era la causante de que la apatía y la tranquilidad sustituyeran al valor y al afán de libertad, que los productos obtenidos por el comercio ocasionaran el gusto por el lujo y el desprecio de la vida sencilla y moderada, y que la búsqueda de placer y comodidad explicara la codicia y el abandono de hábitos sanos.

Esta inquietud llevó a ver al bárbaro como el ente que se había mantenido puro de los excesos de la vida cultivada. Tácito es uno de los autores que concibió esta imagen y el precursor de lo que se ha llamado «el buen salvaje». Él enumeraba las cualidades físicas y morales de los germanos: eran fuertes y acostumbrados a las fatigas, no les importaba el oro ni la plata, preferían usar el trueque como medio de cambio, los reyes no ejercían un poder absoluto y los jefes militares eran apreciados por su valor, gozaban de gran libertad en las asambleas y participaban activamente en la toma de decisiones. En la misma línea, los libertos no tenían influencia pública ni privada. No había grandes banquetes y espectáculos, el matrimonio era respetado, el adulterio poco frecuente, y la usura desconocida ${ }^{11}$. Al hacer esta descripción, Tácito no sólo busca narrar aspectos referentes a la organización política, económica y social de los germanos como un simple tratado de corte etnográfico, sino que tiene otros objetivos. Tácito imagina un bárbaro y sus virtudes -antítesis del romano y sus vicios- con una intención moral: oponer la vida sana y las costumbres de los germanos a la degeneración de la sociedad romana de su tiempo que estaba alejada de los valores republicanos. Como a varios romanos, le inquietaba la situación de Roma después de haber conquistado varios territorios e instaurado el régimen personal de poder. La nobleza, con la que se

\footnotetext{
9 Caes. BG 1.1. Traducción de Rubén Bonifaz Nuño.

10 Tac. Agr. 21.2.

11 Tac. Germ. 5-14, 19-26.
} 
identifica, consideraba las guerras púnicas como el fin del esplendor romano; después las antiguas virtudes romanas se degradaron, la riqueza y el lujo trajeron la ambición y la avaricia con la consiguiente ruina de las costumbres que hicieron grande a Roma. Por ello en la Vida de Julio Agrícola y en la Germania, presenta a los bárbaros como pueblos que se apegaban a la libertad y guardaban intactas las cualidades que los hacían vigorosos en los planos físico y moral. Así, Tácito usa a los bárbaros para hacer una crítica de la sociedad de su tiempo al oponer su ansia de libertad al servilismo de los senadores ante el príncipe ${ }^{12}$.

Sea el salvaje o el hombre de costumbres puras, la imagen del bárbaro servía para que los romanos tomaran distancia de él. Empero, cualquier visión del bárbaro producía una imagen atemporal y fija que no permitía alteraciones: el bárbaro era uno y el mismo desde que el mundo clásico tuvo contacto con él, pues los atributos vinculados a ellos pertenecían a una naturaleza inmutable a través del tiempo. Los cambios ocupan un lugar marginal en estas descripciones e interesan poco, lo relevante es que los rasgos se señalan una y otra vez, de modo que la imagen se consolida. De tal forma, las mutaciones ocupan un lugar secundario a la hora de definir una identidad. No obstante, la visión del bárbaro ignoraba los cambios que se produjeron en sus sociedades. Los bárbaros que asolaron el Imperio desde el siglo II d.C., no eran los mismos que Julio César y Tácito vieron. La propia Roma tuvo un papel activo en los cambios estructurales de las sociedades bárbaras al inmiscuirse en sus asuntos internos, al colocar reyes que colaboraran con ella, al instaurar nudos comerciales para propiciar la entrada de productos y utensilios de la vida romana más allá de las fronteras, al permitir y alentar el ingreso de bárbaros al ejército romano de acuerdo con varias modalidades que los ponían en contacto con armas y tácticas romanas, y al consentir el asentamiento de pueblos bárbaros en territorio romano ${ }^{13}$.

A pesar de estos cambios en las sociedades bárbaras, y de que el bárbaro estaba muy lejos de tener los rasgos inamovibles y atemporales que pretendían los romanos, su imagen no se modificó en términos sustanciales. Desde la época de Marco Aurelio, en que las luchas con los bárbaros se hicieron más frecuentes y duras, el perfil que tenían a los ojos romanos se fue haciendo cada vez más severo y los rasgos negativos que se les atribuía cobraron mayor fuerza. La visión del buen salvaje se fue borrando y desaparece prácticamente en el siglo II d.C. Los ataques bárbaros y las derrotas romanas ante ellos, que habían provocado la ruina de ciudades, la pérdida de bienes y cosechas, la captura de habitantes y la pérdida de territorios, no eran fáciles de olvidar y eran motivo frecuente de rencor y temor. Sucesos como la muerte de Decio enfrentando a los godos en 251 d.C., la captura de Valeriano por los persas en 259 d.C. y la derrota de Valente frente a los visigodos en 378 d.C. en Adrianópolis, entre otros, fueron eventos muy dolorosos para los romanos. Estos hechos hacían recordar antiguas derrotas ante los galos

12 Sobre la forma en que los romanos expresaban sus opiniones en boca de otros vid James (2000: 277-79). Para la historiografía moral y crítica romana vid Musti (1998: 216-22).

13 Thompson (1982: 7-14); Dixon y Southern (2000: 47-49); Heather (1999: 236-48); Burns (2003: 248-84). 
en 390 a.C., o Cannas en 216 a.C. ante Aníbal. Así, Amiano, para denotar la importancia de la derrota en Adrianópolis y sus efectos funestos, no halla mejor símil que Cannas ${ }^{14}$. En la mente de los pensadores romanos ya no había sitio para el bárbaro de costumbres puras; al contrario, sus rasgos se afirmaron como malos, siendo ese retrato el que perdura.

Los escritores del Bajo Imperio recuperaron viejas representaciones del bárbaro para remarcar sus características negativas. Entre éstas estaba su nomadismo que los ubicaba en el lugar más bajo de la escala humana al no tener leyes y dejarse llevar por sus impulsos, lo cual acentuaba su carácter guerrero y evitaba que tuvieran una vida sedentaria y agrícola. Hablando de los godos, Sinesio aducía como muestra de falta de cultura que no tuvieran grandes ciudades ni una organización política que se acercara a la del mundo antiguo; son entes primitivos con una educación diferente y costumbres atrasadas que tienen más en común con las bestias que con los hombres ${ }^{15}$. La descripción de Amiano sobre los hábitos hunos va en el mismo tenor: las relaciones sexuales no tienen restricción, los jóvenes son acostumbrados a las privaciones para ser buenos guerreros, visten ropas paupérrimas que los dejan semidesnudos, la caza de animales es la fuente esencial de alimento y no edifican templos. Sobre su alimentación dice: «con aspecto humano a pesar de su rudeza, llevan una vida tan agreste que no precisan fuego, ni alimentos sabrosos, sino raíces de hierbas salvajes. Se alimentan con carne de cualquier animal casi cruda, ya que sólo la calientan ligeramente colocándola entre sus piernas y los lomos de sus caballos» ${ }^{16}$.

Otro rasgo negativo era el carácter bélico, sanguinario y cruel; los bárbaros, al igual que las bestias, gozaban con las devastaciones y matanzas. Estos vicios congénitos se acentúan en la medida en que más atacaban al Imperio. Su violencia y fiereza quedaban comprobadas con las incursiones que realizaban en territorio romano al no mostrar respeto ni consideración por nada ni por nadie. Jerónimo exclamaba horrorizado desde Oriente: «Godos, sármatas, cuados, alanos, hunos, vándalos y marcomanos devastan, asolan y saquean. ¡Cuantas matronas, cuantas vírgenes de Dios, y personas libres y nobles fueron ludibrio de estas bestias! » ${ }^{17}$. El orador Nazario pregunta: «¿Para qué recordar a los brúcteros? ¿Para qué a los chamavos? ¿Para qué a los queruscos, lanciones, alamanes y tubantes? Sus nombres resuenan a una señal de guerra, y la ferocidad bárbara muestra horror en las mismas palabras " ${ }^{18}$. Amiano acusa de «enemigos crueles y persistentes» a los germanos; "pueblo de crueldad reconocida» a los alamanes; y «bestias excitadas por el olor a sangre» a los godos. El común denominador de estos adjetivos es que esos pueblos se deleitan en infringir daño y sufrimiento ${ }^{19}$. A medida que los con-

14 Amm. Marc. 31.13.19.

15 Sinesio, De Regno 25a.

16 Amm. Marc. 14.4; 31.2. Traducción de María Luisa Harto Trujillo. 2.14.1.

17 Hieron. Ep. 60.16. Traducción del autor. Cf. Hdn. 3.14.8; Claud. B.Gild. 163-168; Rut. Namat.

18 Pan. Lat. 10.18.1. Traducción del autor. Una cita similar en Hdn. 3.14.8.

19 Amm. Marc. 21.11.2, 26.5.7, 31.15.2. Traducción de María Luisa Harto Trujillo. Sobre el uso del mundo animal para referirse a los bárbaros en la obra de Amiano, vid Blockey (1975: 115). 
flictos militares con los bárbaros se agudizaban, los romanos recalcaban los estereotipos con los que percibían a sus enemigos y sus juicios se volvían más severos. Las derrotas y las ocupaciones de tierras dentro del Imperio fueron un golpe muy duro para los escritores antiguos, quienes veían en estos sucesos un peligro inminente para la existencia del poder romano y el reflejo de su grave situación. La necesidad de tomar distancia de los invasores hizo que esos mismos autores recrudecieran su imagen negativa y enfatizaran sus rasgos oscuros, como entes que por naturaleza no eran totalmente humanos y que estaban a gran distancia de los valores que el Imperio representaba. Se resalta también su naturaleza ambiciosa, como Herodiano dice: «por el oro se dejan convencer los germanos, ya que son codiciosos y continuamente están negociando la paz por dinero ${ }^{20}$. A pesar de sus rasgos guerreros, se considera que sus tácticas bélicas son simples, pues buscan el robo y la rapiña, y son inferiores en combate frontal. Son altivos y soberbios al comenzar una batalla, pero cobardes cuando el resultado les es adverso. Además, son pérfidos y traicioneros, Amiano describe así a los hunos: «son desleales y volubles en los acuerdos porque se dejan llevar por el más mínimo soplo de una nueva esperanza, achacando esto a su carácter impetuoso. Semejantes a animales irracionales, no distinguen en absoluto entre lo honesto y lo deshonesto. Sus palabras son ambiguas y enrevesadas, y jamás han respetado una creencia o una religión. Por ello, como arden en deseos de conseguir oro, y son tan volubles e irascibles, en ocasiones llegan a romper en un mismo día varios acuerdos con algún aliado y, sin que nadie intervenga, se reconcilian con él» 21 .

Los romanos sabían que habían sufrido derrotas a manos de los bárbaros, pero preferían adjudicar estos reveses a la incapacidad de un general, a la mala ejecución de una maniobra o a los vicios que veían en el ejército de su tiempo. No contemplaban la posibilidad de que los bárbaros hubieran desarrollado armas y tácticas militares, muchas de ellas ocasionadas por el contacto frecuente con el ejército imperial, capaces de contender contra Roma.

Con esta tipología de bárbaro, no es extraño que se enfatice cada vez más el carácter civilizado del Imperio y la necesidad de preservarlo de estos salvajes entes. Poco antes de que comenzaran los ataques bárbaros, Elio Arístides identificaba claramente al mundo romano con el orbe civilizado como si esas dos esferas fueran indivisibles. Al lado de Roma los demás pueblos importan poco y, cuando son mencionados, se ven insignificantes e insensatos por no participar del orden romano ${ }^{22}$. De modo parecido, el filósofo Celso hacía ver a los cristianos que su negativa de cumplir con los deberes cívicos y formar parte del ejército era una cuestión que se relacionaba estrechamente con la seguridad de Roma y del orbe civilizado. Celso señala los efectos del rechazo cristiano a comprometerse con el Imperio y el riesgo que otros siguiesen su proceder, al decir que si el cristiano no

20 Hdn. 5.15.6. Traducción de Juan J. Torres Esbarranch. Cf. Tac. Ann. 2.13.

21 Amm. Marc. 31.2.11. Traducción de María Luisa Harto Trujillo. Esto era un lugar común como se ve en Tac. Ann. 1.57-58.

22 Aristid. Or. 23.3. 
sirve a la causa de Roma «con razón te castigará el emperador; pues si todos obraran como tú, nada impediría que aquél se encontrará sólo y abandonado y el gobierno de la tierra caería en manos de los bárbaros más sin ley y salvajes, y entonces ni de tu religión ni de la verdadera sabiduría quedaría noticia entre los hombres ${ }^{23}$. De igual forma en el siglo V d.C. Prudencio considera las victorias de Estilicón sobre los bárbaros como los triunfos de la civilización frente a la barbarie; así, en boca de Roma, señala los propósitos de Alarico en su campaña del 402 d.C.: «intentó hace poco un tirano geta destruir Italia y vino desde su Histrio patrio después de haber jurado asolar estos alcázares, deshacer con las llamas mis techos dorados, vestir con zamarras a mis próceres togados» 24 . Una y otra vez se identifica a Roma con el género humano, indicando que quien está fuera de su ámbito difícilmente puede ser humano. Así, los integrantes del Imperio cerraban filas en torno a su seguridad y dejaban ver que la lucha entre éste y el bárbaro implicaba cuestiones fundamentales. No era una confrontación entre iguales, sino una disputa entre los valores positivos que Roma representaba y los vicios que ocasionaría el caos bárbaro.

Tampoco la visión de algunos cristianos sobre los bárbaros se diferenciaba mucho de la de un pagano. Es cierto que durante las persecuciones de Decio y Valeriano en el siglo III d.C., Hipólito y Comodiano veían a los bárbaros como los causantes de la caída de la Roma pagana e idólatra; eran ellos los ejecutores del castigo divino al Imperio que perseguía a los siervos de $\operatorname{Dios}^{25}$. De modo similar había cristianos que juzgaban que la conversión era una condición esencial para civilizar a los bárbaros y resaltaban los efectos del cristianismo en ellos, pues los bárbaros dejaban las armas para trabajar los campos y vivir en paz con los romanos ${ }^{26}$. Sin embargo, esto no se tradujo en acciones concretas para evangelizarlos: las conversiones fueron gracias a iniciativas personales de misioneros que usaban habilidades y medios que ellos mismos se procuraban. Esto explica que los bárbaros mayoritariamente se convirtieran a la modalidad arriana y que la Iglesia tardara bastante tiempo en mandar obispos a las comunidades cristianas que lo pedían ${ }^{27}$. Algo que influyó fue la actitud poco favorable de algunos cristianos hacia la capacidad y entendimiento de los bárbaros. Así, Thompson cita la opinión de un romano arriano que, aunque admitía que Dios llamaba a romanos y a bárbaros, dudaba que el mensaje cristiano pudiera florecer entre «poblaciones incultas, indisciplinadas y bárbaras, que ni lo solicitan ni lo escuchan con juicio y que tienen el nombre de cristianos pero los modos paganos" ${ }^{28}$. Otro aspecto que debe señalarse es que, a partir de Constantino, los cristianos empezaron a gozar de una mejor situación;

${ }^{23}$ Origen. C.Cels. 8.66. Traducción de Daniel Ruiz Bueno. En la propaganda oficial, el bárbaro desea acabar con el orden romano, por lo que los emperadores destacan su papel de restitutor orbis. Además, monedas e inscripciones proclaman la victoria Augusta, securitas perpetua y la Roma aeterna para enfatizar su protección de la ley y la cultura frente a la amenaza bárbara. Mazzolani (1970: 196).

24 Prudent. C.Symm. 2.700-705. Traducción de Luis Rivero García.

25 Mazzarino (1961: 35-38).

26 Orígen. C.Cels. 8.68; Lactant. De Mort. Pers. 3.5; Oros. 7.41.7.

27 Thompson (1989: 80-83). No obstante, Orosio señala que, a petición expresa de los godos, el emperador Valente envió misioneros arrianos para predicarles el Evangelio. Oros. 7.33.53.

28 Thompson (1989: 85). 
así estaban dispuestos a defender al Imperio que les aseguraba una condición privilegiada. En este contexto, el bárbaro como el instrumento divino que castiga a Roma no tenía sentido, y los cristianos adoptaron la representación tradicional pagana respecto a los bárbaros. Prudencio enuncia claramente la opinión que él y muchos de sus coetáneos tenían cuando afirma que «distan lo romano y lo bárbaro como separación hay entre un cuadrúpedo y un bípedo o entre lo mudo y un ser dotado de habla». ${ }^{29}$ Sinesio, quien como obispo había realizado la defensa de Cirene frente a los bárbaros, calificaba a los godos como una raza que «desde antiguo se ha mostrado a los ojos de los romanos como muy apta para la esclavitud y la más merecedora de ella»30. Por su parte, Orosio, aunque no era contrario a los godos, no creía que fueran capaces de desarrollar un sistema legal y una organización política avanzada, lo que explicaba el papel que debían tener. Dice que Ataúlfo deseaba suplir al Imperio, pero «cuando la experiencia probó que ni los godos, a causa de su desenfrenada barbarie podían en absoluto ser sometidos a leyes, ni convenía abolir las leyes del Estado, sin las cuales un Estado no es Estado, prefirió buscar su gloria mediante la recuperación total y el engrandecimiento del Imperio Romano con la fuerza de los godos y ser reconocido por la posteridad como el autor de la restauración de Roma, después de no haber podido ser su sustituto „ ${ }^{31}$.

Incluso cuando los romanos debieron convivir con los bárbaros, tratar con ellos o hacerles frente, no los veían en términos de igualdad. Por ejemplo, Orosio decía que la función de Alarico era «luchar fielmente a favor del emperador Honorio y gastar las fuerzas godas en defensa del Estado romano „32. A pesar del influjo romano y las transformaciones bárbaras, los romanos persistían en sus patrones habituales de pensamiento. Prejuicios, educación y sentimiento de superioridad jugaron un papel decisivo en esa actitud. Como indican Peter Brown y Peter Heather, la sociedad romana fue incapaz de asimilarlos totalmente, pero tampoco pudo deshacerse de ellos. Por esto, los romanos siguieron usando los retratos tradicionales negativos de la literatura antigua para referirse a ellos ${ }^{33}$. Aunque los reyes bárbaros adoptaran títulos y usos romanos, copiaran la administración romana y la nobleza bárbara se vistiera y tuviera las mismas propiedades y lujos de los potentes romanos, los escritores romanos seguían diciendo que eran incultos y salvajes; en otras palabras, lo romano seguía siendo lo óptimo y lo bárbaro inferior. Sidonio Apolinar resalta las virtudes visigodas porque se asemejan a las romanas; incluso su rey se interesaba por el derecho y la literatura latina. Para explicar la cooperación de la nobleza romana con los visigodos, decía que éstos eran cada vez menos bárbaros y estaban llegando a la fase superior de romano ${ }^{34}$. Salviano de

29 Prudent. C.Symm. 2.815-820. Traducción de Luis Rivero García.

30 Sinesio De Regno. 23d. Los ataques bárbaros en su tierra natal le harán decir: «Que los malvados, los malditos bárbaros perecieran de mala manera, es lo que yo había pedido a Dios» (Or. 1.305d). Traducciones de Francisco Antonio García Romero.

31 Oros. 7.43.6. Traducción de Eustaquio Sánchez y Salor. Sobre este pasaje vid Chrysos (1997: 12-13).

32 Oros. 7.43.3. Traducción de Eustaquio Sánchez y Salor.

33 Brown (1989: 146-47); Heather (1999: 236-38).

34 Heather (1999: 243-48). Sobre cómo los reinos bárbaros se apropiaron de elementos romanos, ver Pohl (1997: 33-34). 
Marsella indicaba que había quienes preferían estar con los bárbaros porque estaban hartos de los abusos en territorio romano y buscaban la humanidad romana entre bárbaros al no tolerar la inhumanidad bárbara entre romanos ${ }^{35}$. Lo notable es que lo romano equivale a lo humano y lo bárbaro a lo inhumano. El prestigio del nombre romano era tan patente que motivó al rey Teodorico a afirmar que un godo deseaba ser un romano y sólo un romano pobre querría ser godo ${ }^{36}$. Esta reputación fue recuperada por el obispo africano Víctor de Vita al usar la oposición romano-bárbaro y añadir la de católico-arriano en el marco del destierro de católicos por parte de los arrianos en la África vándala. Por su parte, el jefe britano Corotico, debido a la misión de Patricio en Irlanda, decía que los bárbaros irlandeses no podían aspirar a ser considerados conciudadanos de los romanos ${ }^{37}$. Las virtudes romanas siguieron considerándose superiores y la imagen negativa del bárbaro se propagó a través del tiempo y se adjudicó a otros. Esto ha ocasionado que la imagen del bárbaro que construyeron griegos y romanos se reprodujera en otras épocas, con algunas variantes, únicamente cambiaron los sujetos de tal recreación. La insistencia de ver al otro con rasgos nocivos contribuyó a la negativa romana para integrar a los bárbaros en términos positivos dentro de su sociedad tal y como lo había hecho con otros pueblos durante su historia. La incapacidad de Roma de crear espacios de entendimiento con los bárbaros avivó los conflictos entre ambos y propició, en parte, que la mitad occidental fuera ocupada por los invasores. Actualmente las sociedades occidentales modernas deben convivir con muchos otros y existe la fuerte tentación, por lo menos en algunos grupos dentro de aquéllas, de representarlos en términos negativos. Los desacuerdos y estereotipos suelen presentarse como algo normal en esas relaciones, así como situaciones de hostilidad y rechazo. Falta ver si Occidente desarrolla nuevos mecanismos de trato hacia estos grupos o se mantiene en la dicotomía excluyente que vivió Roma.

\section{BIBLIOGRAFÍA}

ALFÖLDY, G. (1987), Historia Social de Roma, Madrid.

ALGONZA ROLDÁN, M. y MUÑOZ, F. (1993), «La confluencia de culturas en el Mediterráneo Antiguo», en Muñoz, F. ed., Confluencia de Culturas en el Mediterráneo, Granada, 15-56.

ANDERSON, B. (1997), Comunidades Imaginadas. Reflexiones sobre el Origen y la Difusión del Nacionalismo, México.

BLOCKEY, R.C. (1975), Ammianus Marcellinus. A Study of His Historiography and Political Thought, Brussels.

BROWN, P. (1989), El Mundo en la Antigüedad Tardía. De Marco Aurelio a Mahoma, Madrid.

- (1997), El Primer Milenio de la Cristiandad Occidental, Barcelona.

BROWN, M. y WEBSTER, L. eds., (1997), The Transformation of the Roman World, London.

\footnotetext{
35 Alföldy (1987: 287).

36 Vid Brown (1997: 60).

37 Vid Brown (1997: 79).
} 
BURNS, T. S. (2003), Rome and the Barbarians, 100 B.C.-A.D. 400, London.

CHRYSOS, E. (1997), «The empire in West and East», en Brown, M. y Webster, L. eds., 918.

DIXON, K. y SOUTHERN P. (2000), The Late Roman Army, London.

GALL, O. (2004), «Identidad, exclusión y racismo: reflexiones teóricas sobre México», Revista Mexicana de Sociología 66.2, 221-259.

HERNANDO, A. (2002), Arqueología de la Identidad, Madrid.

HEATHER, P. (1999), «The barbarian in Late Antiquity: image, reality and transformation», en Miles, R. ed., Constructing Identities in Late Antiquity, London, 234-258.

JAMES, P. (2000) «The language of dissent», en Huskinson, J. ed., Experiencing Rome. Culture, Identity and Power in the Roman Empire, London, 277-302.

MAZZARINO, S. (1961), El Fin del Mundo Antiguo, México.

MAZZOLANI, L. S. (1970), The Idea of the City in Roman Thought. From Walled City to Spiritual Commonwealth, London.

MUSTI, D. (1998), «ll pensiero storico romano», en Cavallo, G.; Fedelli, P. y Giardina, A. coords., Lo Spazio Letterario di Roma Antica, Roma, 177-240.

PETROCHILOS, N. (1994), Roman Attitudes to Greeks, Athens.

POHL, W. (1997), «The Barbarian successor states», en Brown, M. y Webster, L, eds., 3347.

THOMPSON, E.A. (1982), Romans and Barbarians. The Decline of the Western Empire, Madison.

- (1989), «El cristianismo y los bárbaros del Norte», en Momigliano, A. ed., El Conflicto entre el Paganismo y el Cristianismo en el siglo IV, Madrid, 71-94. 